healthy foods (75\%), and learning about healthy foods for their families (72\%). Five respondents were on diabetic diets, and three were on weight-loss regimens. Half of those on a special diet indicated that they needed help in adhering to the diet.

When asked, "How would you like to learn more about nutrition?", $69 \%$ asked for newsletters, and $67 \%$ preferred videotape (47\% had a VCR). (Respondents could check more than one method.) Twenty-six percent chose a visit from a health representative; $6 \%$ selected a workshop in the principal author's home with family and friends.

Based on these results, the local Cooperative Extension home economist, working with the Mariposa Indian Health Center staff, produced a videotape entitled, "Native American Recipes Made Healthier - But Still Tasty." The videotape features Miwok homemakers demonstrating traditional ways of preparing deer meat gravy, fry bread, honey berries and vegetables. The homemakers show ways to modify recipes so that they are lower in fat, sodium and sugar, and richer in vitamins and minerals. The videotape has been well received in the Mariposa Native American community. Community leaders have commented that they are pleased with the development of an educational tool that addresses the specific needs and interests of Native American families.

\section{Summary}

In summary, the Native Americans living in California's Mariposa-Yosemite region report a number of positive eating habits that contribute to their well-being. A few nutritionally detrimental practices may need altering. Reinforcing positive food practices and helping Native Americans adopt alternatives to poor eating habits can reduce health risks. Native Americans living in the Mariposa-Yosemite area have limited opportunities to obtain the foods they need and appear to need information on obtaining help from federally sponsored food and nutrition programs. Finally, a videotape that addresses the expressed nutrition needs and interests of the community has been developed for use in the Mariposa American Indian community.

J. Ikeda is Nutrition Education Specialist, Department of Nutritional Sciences, UC Berkeley; S. Dugan is retired Registered Nurse with Tuolumne Rural Indian Health Project; $N$. Feldman is Cooperative Extension Home Economist, Stanislaus and Tuolumne counties, and R. Mitchell is Nutrition Research Associate, Department of Nutritional Sciences, UC Berkeley, and Tuolumne Rural Indian Health Project.

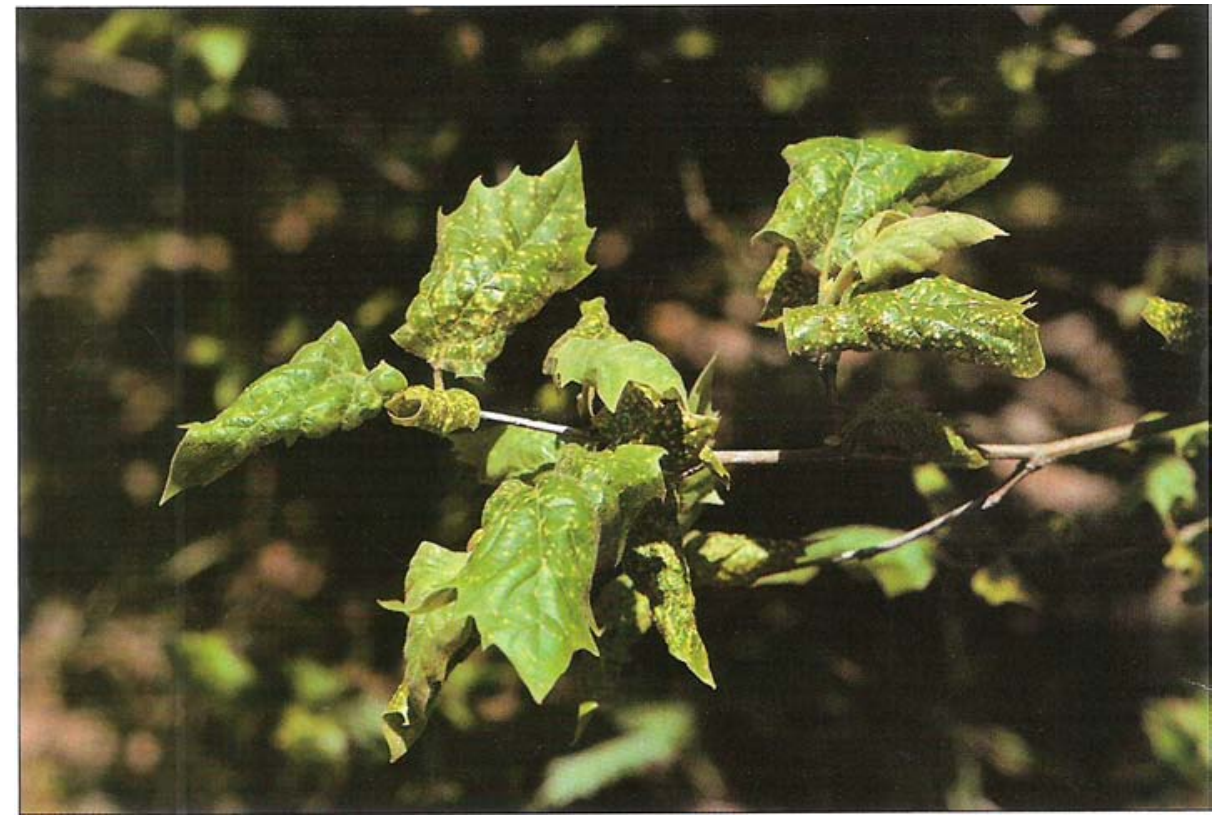

Sycamore scale infestation on untreated trees is seen here.

\title{
Sycamore scale treatments most effective at bud break
}

\section{Pavel Svihra}

\section{Bud break, not a calendar date, is the best time to protect sycamore trees against the sycamore scale, Stomacoccus platani, with insecti- cidal sprays. It is at bud break that the highest density of crawlers ap. pears on twigs.}

Both native and introduced sycamores (Platanus spp.) can be infested by the sycamore scale, Stomacoccus platani Ferris. Considered the most important insect pest of landscape sycamore trees in California, this native scale also occurs in Nevada.

The most visible injury is the spotting and distortion of leaves caused by scale insects' feeding and the premature loss of portions of such foliage. Less known is the effect of bark feeding by a substantial scale population.

Earlier researchers outlined the seasonal history of the sycamore scale as follows: Except for exposed scales, the insects overwinter on woody tree parts in bark fissures and beneath bark flakes and plates. Eggs are laid there late in winter and crawlers move to new leaves as they appear. After they finish feeding, mature individuals leave their substrate, mate, and the females deposit eggs in masses, mostly on woody parts of trees, to begin the next generation. This cycle is repeated several times during the growing season.

The standard measure for sycamore scale control, developed in Southern California, has been the application of horticultural oil during January, the dormant season. The application reportedly coincides well with the occurrence of the first or second instars, when they are particularly susceptible to oil. Also, application during the dormant period ensures maximum coverage of trees owing to the absence of leaves at that time.

In Northern California, however, pest control applicators have expressed disappointment with the degree of scale control achieved with dormant season sprays of oil. Complaints usually focused on the high levels of leaf loss during the growing season, not the extent of leaf spotting or distortions noted.

The timing of sprays to control sycamore scale in Northern California was 


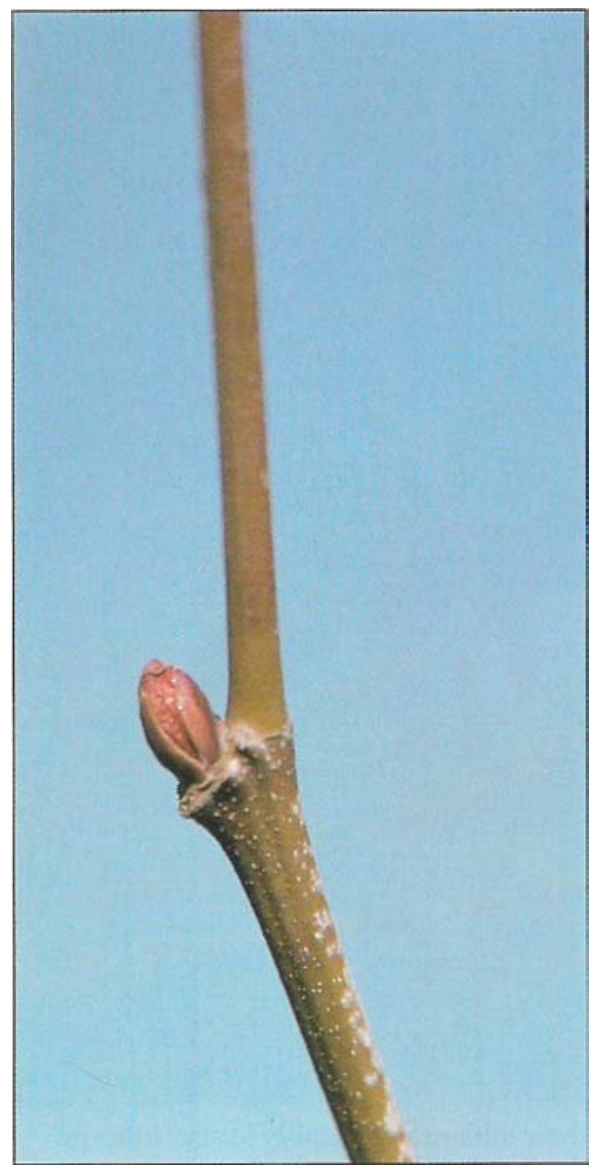

Some treatments were timed at bud break.

re-evaluated with a series of trials in Marin and Contra Costa counties during 1989 and 1991. Ancillary biological studies were made in Alameda County in 19891990.

\section{Procedure}

Hydraulic sprays, at 200 psi pressure, were applied to landscape London plane trees, 12 to 20 feet tall, at various times during the dormant and early growing seasons. All experiments utilized a completely randomized design with singletree plots. Two to four persons counted scale-caused spots on entire leaves, or within 4- $\mathrm{cm}^{2}$ areas along the midvein of leaves taken from the four cardinal compass directions of each tree. Leaves chosen for sampling were always the second one from the base of current season shoots. Experimental trees were also monitored biweekly during the growing season to assess the treatment's effect on leaf loss.

To follow scale crawler movement, two-sided sticky tape, 0.5 inch wide, was attached in encircling bands to twigs on five scale-infested trees in Albany, California. Four bands, oriented in accordance with the cardinal compass directions, were attached to each tree. We used twigs ranging in circumference from 2.8 to $7.7 \mathrm{~cm}$ and averaging $5.1 \mathrm{~cm}$. Bands were collected weekly during most of the year, biweekly from mid-December to mid-January, and were replaced with new bands on the same positions on the twigs from which they were collected. Trapped crawlers were counted in the laboratory under magnification.

Nearby, four current season shoots were tagged on each of five trees, and their leaves numbered consecutively starting at the shoot base. Beginning May 9, 1989 , numbers of scale-caused spots on all leaves were counted weekly. Leaf surface area was also measured on each sampling date. The date of leaf drop, to the time of last scale counting, was noted.

\section{Results}

Satisfactory protection against sycamore scale infestation was afforded by horticultural oil and by oil plus diazinon, when application was made to dormant trees in late January (table 1, trial 1). Diazinon alone applied at that time was ineffective. It also did not appear that adding diazinon to oil contributed to scale control beyond that provided by oil alone. Interestingly, oil or oil-diazinon combinations failed completely when applications were made 1 month later in the dormant season (table 1, trial 2). In spite of the significant effect of oil and oil plus diazinon in trial 1, scale density was too high on leaves and they massively dropped in July and August. Mid-July surveys of trees in both trials found no differences in the density of treated and untreated foliage dropped under the sycamores.

When spray applications were made at bud break or at early leafing-out, a high level of scale control was achieved (table 2). Again, there appeared to be no advantage to combining diazinon with oil, since oil or diazinon alone was equally effective. Besides good scale control, foliage appeared greener on treated trees than on controls; treated trees looked healthier, and only a few leaves dropped because the scale attacks on leaves remained low. In contrast, we counted up to 100 dropped leaves under untreated trees in July and August.

Earlier investigations noted that in January, all scales are in the first or second instars. This synchrony may well explain why January applications were effective and February ones were not. The efficacy of treatments coinciding with bud break or early leafing is explained by reference to figure 1. Late March, when sycamore trees begin to break bud, is the time when huge numbers of crawlers begin to appear. For example, in 1990 an average of more than 6,000 were trapped on each sticky band on
April 4. When that generation of scales is reduced with a bud-break application, survivors are apparently unable to produce the second large influx of crawlers that normally occurs in June-July and subsequent scale generations.

From these data it appears that bud break applications are more effective and reliable than those made in the dormant season. Bud break occurs after favorable local conditions develop for the resumption of sycamore growth. The same conditions trigger the scale crawlers' response

TABLE 1. Effect of horticultural oil and diazinon, alone and in combination, on sycamore scale reduction, San Ramon, California, 1989

\begin{tabular}{cc}
\hline \hline & Avg. no. scales per \\
Treatment $^{*}$ & $4-\mathrm{cm}^{2}$ area, on $6 / 30 \dagger$
\end{tabular}

Trial 1. Applied 1/22

Volck supreme oil, 2 gal

Volck supreme oil, 2 gal + $7.2 \mathrm{a}$ diazinon 50W, $1 \mathrm{lb}$

Diazinon 50W, $1 \mathrm{lb}$ $33.2 \mathrm{~b}$

Untreated $28.6 \mathrm{~b}$

Trial 2. Applied 2/22 $\ddagger$

Volck supreme oil, $1 \mathrm{gal}$

Volck supreme oil, 2 gal

Volck supreme oil, $1 \mathrm{gal}+$

diazinon 50W, $1 \mathrm{lb}$

Untreated

$14.2 \mathrm{a}$

*Rate per 100 gallons of water.

†Based on eight leaves sampled from each tree. For each trial, means followed by the same letter do not differ significantly at the $5 \%$ level according to Duncan's multiple range test.

¥Seven replications in trial 1 ; six replications in trial 2.

TABLE 2. Effect of various insecticides on sycamore scale reduction, Corte Madera and Alamo, California, 1991

\begin{tabular}{ll}
\hline Treatment ${ }^{*} \quad$ Avg. no. scales per leaft
\end{tabular}

Trial 1. Applied 3/29

Volck supreme oil, $1 \mathrm{gal}$ 1.5 a Untreated

Trial 2. Applied 3/29‡

Volck supreme oil,

$1 \mathrm{gal}+$ diazinon AG 500, $1 \mathrm{pt}$ 24.6 b

Trial 3. Applied 3/29

Diazinon AG 500, 1 pt $24.0 \mathrm{~b}$

Trial 4. Applied 4/4

Malathion 4E, 1 qt

${ }^{\star}$ Rate per 100 gallons of water.

†Evaluations made on $6 / 11$ in trials 1,2 and 3 ; on $6 /$ 14 in trial 4. Based on four leaves sampled from each tree. For each trial, means followed by the same letter do not differ significantly at the $5 \%$ level according to Duncan's multiple range test. $\ddagger$ Three replications in trials 1,2 and 3 ((Corte Madera); six replications in trial 4 (Alamo). 


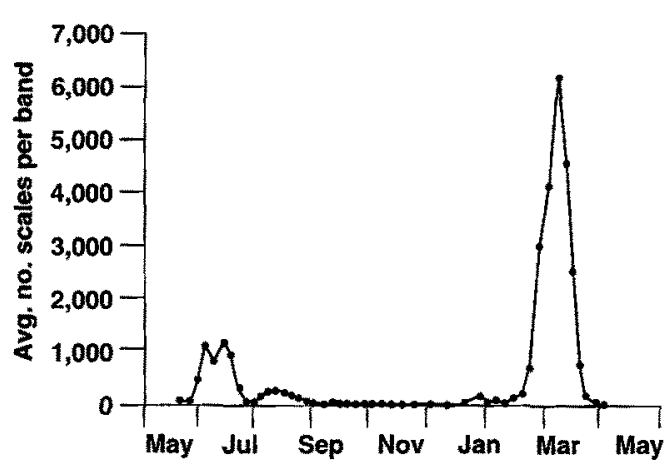

Fig. 1. Sycamore scale crawlers trapped on sticky bands at Albany, California, 1989-90.

to the twigs. By synchronizing insecticidal treatment with bud break, the pest manager negates guessing, kills crawlers when they are present in the highest density, and applies insecticides in the absence of any appreciable amount of foliage that might compromise thorough tree coverage.

Interestingly, crawlers were trapped on sticky bands during every month of the year. Those that occur during the period when sycamore trees are leafless apparently utilize twig bark as a feeding substrate.

On nonpollarded sycamore trees, an average of four to six leaves are borne per Periodic counts of scale-caused spots on living leaves on tagged shoots indicated that the more basal leaves become heavily shoot, with the basal leaf appearing first.

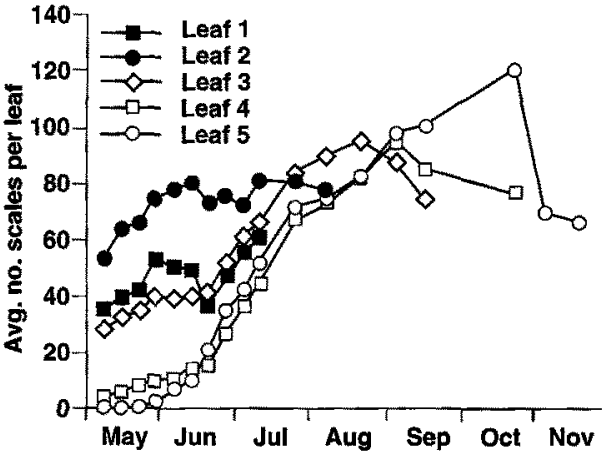

Fig. 2. Progression of sycamore scale infestations on basal leaf (Leaf 1) to terminal leaf (Leaf 5) on shoots at Albany, California, 1989.

infested first (fig. 2). Over time, however, leaves toward the shoot terminals become increasingly more infested than the basal ones, but because terminal leaves become larger in size than basal leaves, scale density remains less. The apparent decline in scale numbers seen toward the end of the growing season, on leaves 3,4 , and 5 , is believed to be an artifact attributable to the more heavily infested leaves dropping prematurely, resulting in increasingly fewer leaves on which to base the average values shown in figure 2 .

Determining the contribution of sycamore scale to the premature loss of leaves proved to be an elusive undertaking, and to date has not been elucidated unequivocally. Scale density was found to be highly

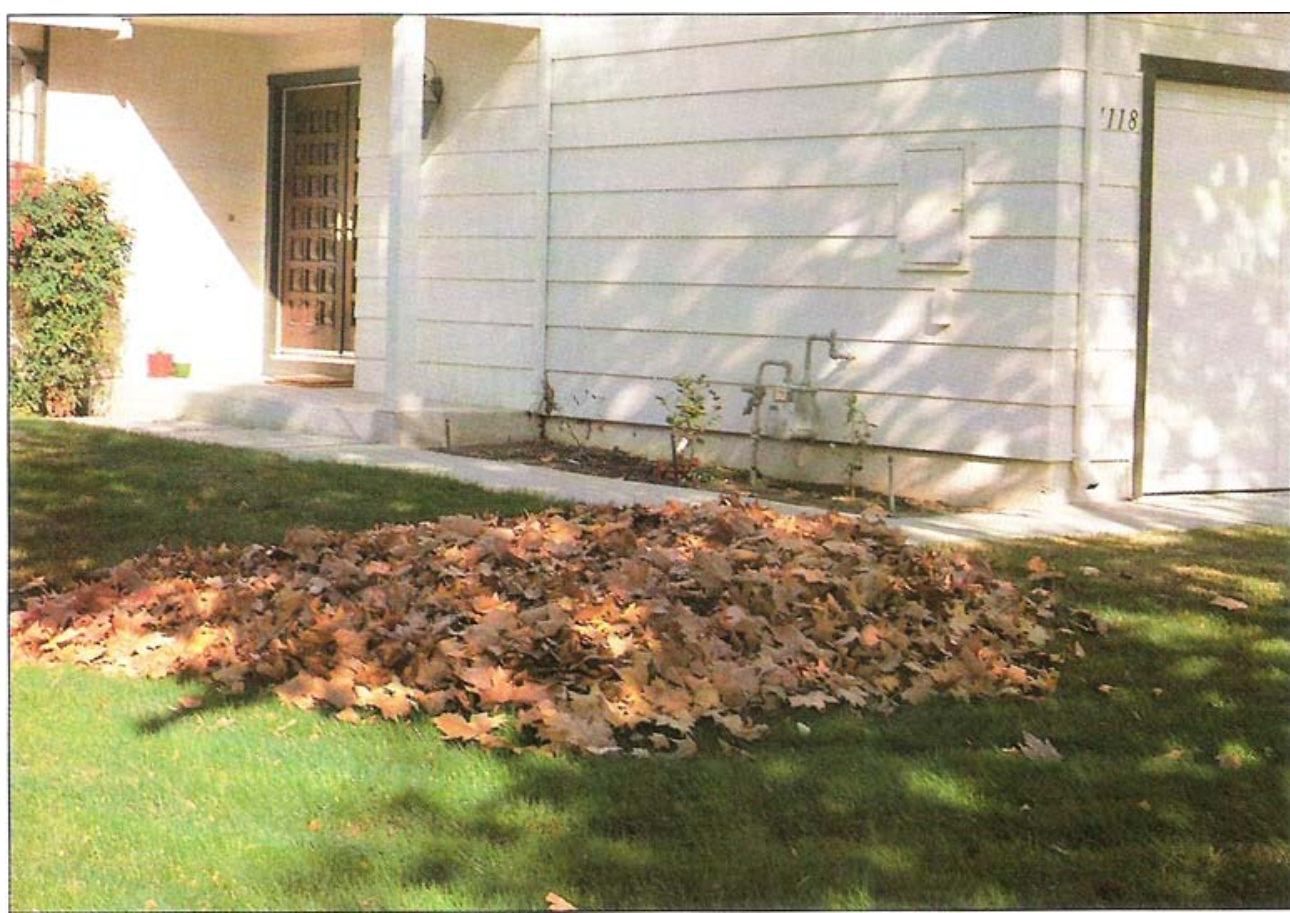

Leaves were piled in midsummer after they dropped from trees infested by the sycamore scale.

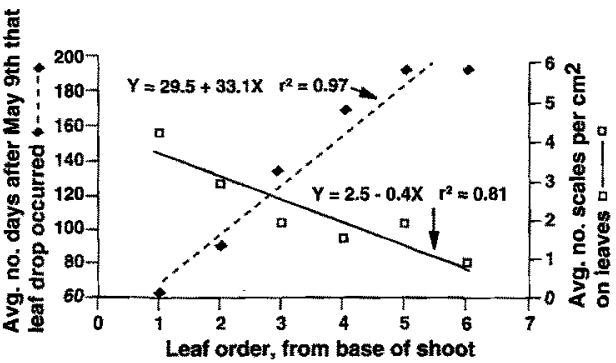

Fig. 3. Linear regressions of date of leaf drop and scale density on leaf order from base of shoot at Albany, California, 1989.

and negatively correlated with leaf order on shoots; that is, the basal leaf supported the highest scale density and the terminal leaf the least (fig. 3). The date of leaf drop was also highly and positively correlated with leaf order, with the basal leaf dropping first and the terminal leaf last. Further investigation, using plant material with and without scale present, may allow this relationship to be established conclusively. However, field observations in the scale management trials described earlier make it clear that trees on which scale numbers are reduced to low levels retain their foliage appreciably longer into the season than do untreated control trees.

\section{Conclusions}

The series of chemical treatments applied in the dormant season and at bud break to control sycamore scale revealed that dormant sprays applied in February can fail; instead, applications should be synchronized with bud break. Bud break development can be easily monitored by a pest control advisor and supports a more rational approach to foliage protection since each treatment significantly reduces scale numbers. Additionally, bud break treatment with any of the tested insecticides may be combined with chlorothalonil to control sycamore anthracnose caused by Apiognomonia platani.

P. Svihra is Horticulture Advisor, Marin/ Sonoma counties; C. F. Fouche is Staff Research Associate, Department of Entomological Sciences, UC Berkeley, and C. S. Koehler is Entomologist Emeritus, Department of Entomological Sciences, UC Berkeley.

The authors thank Steven A. Ash, Gardeners' Guild, for helping to set up an experiment in Corte Madera as well as Richard Molinar, Al Redo and John Basenese for help with sampling and setting experimental plots. Partial funding for this research was provided by the Cheoron Chemical Company and the California Association of Nurserymen. 